\title{
PENGEMBANGAN SITUS E-LEARNING DENGAN MOODLE VERSI 3.1 SEBAGAI MEDIA PEMBELAJARAN PADA PROGRAM STUDI PENDIDIKAN GURU MADRASAH IBTIDAIYAH
}

\author{
Hamdan Husein Batubara
}

Universitas Islam Kalimantan Muhammad Arsyad Al Banjari Banjarmasin

Email: hamdanhusein@fsi.uniska-bjm.ac.id

\begin{abstract}
ABSTRAK
Penelitian ini bertujuan untuk membuat situs e-learning dengan Moodle versi 3.1. dan mengkaji hasil penggunaannya sebagai media pembelajaran pada Program Studi Pendidikan Guru Madrasah Ibtidaiyah. Penelitian ini menggunakan desain penelitian dan pengembangan (research and development) untuk menghasilkan sebuah situs e-learning. Dosen dan mahasiswa mendaftar pada situs e-learning dilakukan secara mandiri dengan e-mail. Pengguna yang berhasil mendaftar pada situs e-learning akan mendapatkan peran authentical user (pengguna terdaftar). Authentical user dapat mengikuti sebuah mata kuliah dengan cara mendaftar menggunakan sandi mata kuliah. Administrator memberikan peran Manager kepada akun dosen agar ia dapat mandiri dalam membuat dan mendaftarkan dirinya sebagai pengajar pada sebuah halaman mata kuliah. Fitur-fitur untuk menyajikan bahan ajar terdiri dari format buku, halaman tunggal, file, folder, dan URL. Aktivitas pembelajaran yang tersedia adalah forum diskusi, penugasan online, ujian online, feedback, dan kuesioner online. Rata-rata skor ahli media menyatakan bahwa kualitas e-learning berada pada kategori baik dan para pengguna percaya bahwa e-larning efektif digunakan sebagai media pembelajaran. Produk yang dikembangkan telah memenuhi saran ahli media dan para pengguna e-learning.
\end{abstract}

Kata Kunci: Media Pembelajaran, E-Learning, Moodle

\begin{abstract}
This study aims to create an e-learning site with Moodle version 3.1. and review the results of its use as learning media in the department of elementary school teacher education. This research uses research and development design to produce an e-learning website. The registration method on the e-learning site is email-based self-registration. Users who successfully register on the e-learning site will get the authentical user role. Authentical users can register on a course by using a course password. The administrator assigns the Manager role for the lecturer's account so that they can create and enroll himself as a teacher on a course page. Every
\end{abstract}

AL-BIDAYAH: Jurnal Pendidikan Dasar Islam Volume 9, Nomor 1, Juni 2017; ISSN: 2085-0034 
teacher has obligation to present matter with single page, or file, or folder, or URL. Teacher can add learning activities using forums, online assignments, online exams, feedbacks, and online questionnaires. The average score of media experts states that the quality of e-learning is in good category and e-learning users welcome the use of e-learning as a medium of learning and assessment. The products developed have met the advice of media experts and e-learning users.

\section{Keyword: Learning Media, E-Learning, Moodle}

\section{A. PENDAHULUAN}

Pemanfaatan Teknologi Informasi dan Komunikasi pada bidang pendidikan telah melahirkan suatu model pembelajaran elektronik atau yang dikenal dengan e-learning. E-Learning yang merupakan singkatan dari electronic learning berarti pembelajaran dengan menggunakan bantuan perangkat elektronika, khususnya perangkat komputer. Dalam perkembangannya, e-learning dikenal juga dengan istilah on-line course, online learning, internet-enabled learning, virtual learning atau web based learning. ${ }^{1}$

Penggunaan e-learning di Indonesia berkembang sejalan dengan perkembangan infrastruktur ICT. Beberapa program pengembangan ICT khususnya infrasruktur di Indonesia adalah sebagai berikut: 1) 19992000: Jaringan Internet (Jarnet), 2) 2000-2001: Jaringan Informasi Sekolah (JIS), 3) 20022003: Wide Area Network Kota (WAN Kota), 4) 2004-2005: Information and Communication Technology Center (ICT Center), 5) 2006-2007: Indonesia HigherEducation Network(Inherent), 6) 2007-sekarang: Jejaring Pendidikan Nasional (Jardiknas), 7) 2008-sekarang: Southeast Asian Education Network (SEA EduNet)

Dengan berkembanganya penggunaan internet, munculah situs e-Learning yang awalnya menjadi media sharing berbagai materi pembelajaran, di antaranya http://www.

1 Darmawan, D. Pengembangan E-Learning: Teori dan Desain. (Bandung: PT. Remaja Rosdakarya, 2014), hlm. 15. ilmukomputer.org dan http://www.e-dukasi. net. Namun seiring dengan perkembangan infrastruktur ICT tersebut maka banyak institusi pendidikan mulai melakukan pengembangan E-Learning. Adapun di antara Perguruan Tinggi yang mengembangkan e-learning menggunakan aplikasi Moodle adalah: ITB (http://kuliah.itb.ac.id/), UNPAR (http://eLearning.unpar.ac.id/), Gunadarma (http://eLearning.gunadarma.ac.id/), ITS (http://share. its.ac.id/), Unibraw (http://inherent.brawijaya. ac.id/vlm/), dan lain sebagainya.

Secara umum, fungsi e-learning terdiri dari tiga macam, yaitu: 1) sebagai suplemen, yakni diprogram sebagai penambah wawasan peserta didik dan sifatnya pilihan, 2) sebagai komplemen, yakni materinya diprogram sebagai pelengkap atau penguat materi yang diterima peserta didik di dalam kelas konvensional, dan 3) sebagai substitusi, yakni e-learning dijadikan sebagai kelas virtual bagi peserta didiknya. Model ketiga ini sudah dilaksanakan oleh beberapa perguruan tingggi di Negara maju dengan tujuan untuk memberikan kebebasan kepada peserta didik untuk mengelola kegiatan perkuliahannya sesuai dengan waktu dan aktivitas sehari-hari peserta didik. ${ }^{2}$

Pemanfaatan e-learning pada Lembaga Pendidikan telah memberikan beberapa keuntungan. Hasil penelitian Marikar \& Jayarathne mengungkapkan bahwa

2 Ibid. 
penggunaan e-learnig Moodle di General Sir John Kotelawela Defence University Srilanka mendapat respon positif dari para penggunanya dan dapat meningkat prestasi belajar peserta didiknya. ${ }^{3}$ Hasil penelitian Martín-Blas juga mengungkapkan bahwa penggunaan e-learnig sebagai ruang virtual guru dan peserta didik efektif dalam memperkuat pengetahuan dan kemampuan peserta didiknya. ${ }^{4}$

Hasil penelitian Limniou, M., \& Smith, M mengungkapkan bahwa persepsi guru tentang penggunaan e-learning pada jurusan teknik mampu mengatasi waktu kuliah yang terbatas dan memperkuat pengetahuan siswa. Peserta didiknya juga menyatakan bahwa kesulitan mereka mengenai materi pelajaran dapat difasilitasi dengan menggunakan pendekatan pengajaran yang lebih variatif. ${ }^{5}$

Besarnya peran dan manfaat e-learning bagi dunia pendidikan tidak lepas dari berbagai problematika. Menurut Helmy Anam, terdapat tiga kendala dalam penerapan e-learning pada perguruan tinggi, yaitu: 1) kesiapan infrastruktur, 2) kesiapan dosen dan mahasiswa, dan 3) faktor budaya. Dari segi infrastuktur diperlukan dukungan pemerintah yang lebih intensif agar penerapan teknologi informasi dan komunikasi bisa berjalan maksimal. Selanjutnya dari faktor budaya memerlukan kebiasaan-kebiasaan yang perlu dikembangkan

3 Marikar, F. M. (2016). "Effectiveness of MOODLE in Education System in Sri Lankan University." International Journal of Modern Education and Computer Science, 8(2), hlm. 54.

4 Martín-Blas, T. \&.-F. (2009). The Role of New Technologies in the Learning Process: Moodle as a Teaching Tool in Physics. Computers \& Education, 52(1), hlm. 35-44.

5 Limniou,M.\&.(2010). “Teachers' and Students' Perspectives on Teaching and Learning through Virtual Learning Environments". European Journal of Engineering Education, 35(6), hlm. 645-653. agar kalangan akademis terbiasa dengan metode pembelajaran berbasis e-learning. ${ }^{6}$

Salah satu aplikasi yang banyak digunakan untuk mengembangkan situs e-learning adalah aplikasi Modular Object-Oriented Dynamic Learning Environment atau disingkat dengan MOODLE. Yaitu sebuah platform pembelajaran yang dirancang untuk memberikan pendidik, administrator dan peserta didik sebuah lingkungan berlajar berbasis website dengan berorientasi pada peserta didik dan mempertahankan prinsip-prinsip pembelajaran (social instructional pedagogy). Aplikasi ini dibuat oleh Martin Dougiamas dan telah menjadikannya sebagai aplikasi gratis yang bebas didistribusikan dan dimodifikasi di bawah ketentuan GNU General Public License.

Keunggulan Moodle sebagai e-learning adalah: Pertama, Fiturnya sangat lengkap dan terus berkembang berkat dukungan komunitas Moodle yang sangat besar. Di antaranya ialah untuk komunikasi (chatting, messaging, atau forum), untuk menampilkan bahan ajar atau file materi pembelajaran (page, book, file, folder, URL, $d s b$ ), untuk kegiatan penilaian (assignment, quiz, feedback, choice, survey), untuk melacak dan mengikuti perkembangan proses pembelajaran peserta didik (completion tracking), dan tersedia juga alat untuk menambah fitur standarnya.

Kedua, Moodle memiliki tampilan desain yang logis, sederhana, fitur drag-and-drop, dan tutorial penggunaannya terdokumentasi

6 Kristo, F. Y. (2008, 08 21). Apa Kendala E-Learning di Indonesia?. Diambil kembali dari Detiknet: http://inet.detik.com/read/200 8/08/21/171452/992295/398/apa-kendala-elearning-di-indonesia

7 Admin. (2008, 7 31). Moodle, Portal E-Learning. Diambil kembali dari Kompas Tekno: http:/tekno.kompas.com/ $\mathrm{read} / 2008 / 07 / 31 / 0719116 /$ moodle.portal.elearning

AL-BIDAYAH, Volume 9, Nomor 1, Juni $2017 \mid$ 
dengan baik dalam sebuah website dan tersedia komunitas besar para pengguna Moodle. Di samping itu, seluruh komponen dalam Moodle juga hampir dapat diatur oleh pengguna yang awam sesuai dengan kebijakan dan kebutuhan proses pembelajaran di masing-masing institusi.

Ketiga, Moodle bisa diterapkan pada hampir seluruh jenjang pendidikan. Namun, pada pendidikan pra sekolah dan sekolah dasar hanya bisa difungsikan sebagai pelengkap dan berbagai jenis latihan. Data statistik Moodle menyebutkan bahwa website yang terdaftar memanfaatkan aplikasi Moodle secara resmi sudah mencapai 75.830 website di 232 Negara. Di Indonesia sendiri, terdapat 1374 website yang menggunakan Moodle sebagai aplikasi e-learning. Data ini tentu mengindikasikan bahwa aplikasi Moodle cukup dipercaya sebagai aplikasi E-Learning. ${ }^{8}$

Keempat, Tersedia dalam 120 bahasa dan terus bertambah berkat dukungan terjemahan dari komunitas Moodle yang sangat besar. Bahasa standar Moodle juga dapat diubah oleh pengguna Moodle. Kelima, Aplikasi ini tersedia secara gratis dan bebas terbuka sehingga pengguna diperbolehkan memodifikasinya dan mendistribusikannya sesuai dengan ketentuan GNU pablic license.

Keenam, Aplikasi Moodle dapat beoperasi tanpa harus melakukan modifikasi pada sistem operasi Unix, Linux, Windows, Mac OS X, Netware, dan sistem lainnya yang mendukung PHP, termasuk pada sebagian besar provider web hosting dengan basis data terbaik bagi Moodle adalah MySQL.

Di samping keunggulan tersebut, aplikasi Moodle juga tidak terlepas dari berbagai keterbatasan, seperti ketergantungannya

8 Admin. (2017, 23 2). About Moodle. Diambil kembali dari Moodle: https://docs.moodle. org/32/en/About_Moodle pada jaringan Internet atau LAN membatasi penggunaannya pada wilayah pedalaman yang memiliki jaringan internet kurang baik, dan pilihan bahasa masih kurang sempurna dan membutuhkan waktu yang tidak sedikit untuk mengubah istilah-istilah yang digunakannya.

Dasar pemikiran penulis untuk mengembangkan e-learning sebagai media pembelajaran dan penilaian pada Program Studi Pendidikan Guru Madrasah Ibtidaiyah berangkat dari hasil survei terhadap kesiapan dan kebutuhan dosen dan mahasiswa dalam menggunakan e-learning. Pemanfaatan Teknologi Informasi dan Komunikasi pada Program Studi PGMI sudah diterapkan dalam bidang sistem informasi akademik namun belum dalam bidang pengelolaan pembelajaran. Perangkat TIK yang digunakan oleh sebagian dosen belum optimal untuk kegiatan pembelajaran. Namun, sebagian dosen sudah terbiasa dengan email, media sosial, blog dan Edmodo. Berdasarkan kondisi tersebut, penulis ingin melakukan pengembangan situs e-learning berdasarkan kegiatan penelitian.

\section{B. METODE PENELITIAN}

Penelitian ini menggunakan model penelitian dan pengembangan (research and development). Penelitian dan pengembangan pendidikan sering disebut juga pengembangan berbasis riset yang menghasilkan sebuah produk. ${ }^{9}$ Produk yang dikembangkan dalam penelitian ini adalah media pembelajaran berbasis e-learning menggunakan program Moodle

Subjek penelitian ini adalah seluruh Dosen Program Studi Pendidikan Guru Madrasah Ibtidaiyah yang berjumlah 7 orang

9 Arifin, Zainal, Penelitian Pendidikan: Metode dan Paradigma Baru, (Bandung: PT. Remaja RosdaKarya, 2012), hlm. 126. 
dan mahasiswa Program Studi Pendidikan Guru Madrasah Ibtidaiyah yang berjumlah 172. Mengingat sedikitnya jumlah populasi maka jumlah sampel penelitian ini dimabil $100 \%$ dari seluruh dosen dan $20 \%$ dari seluruh mahasiswa. ${ }^{10}$

Teknik pengumpulan data penelitian ini adalah: 1) Angket, instrumen yang ditujukan kepada ahli media dan calon pengguna e-learning. Hal ini dilakukan untuk memberikan masukan dan perbaikan dalam penyempurnaan e-learning. Review ini peneliti percayakan kepada ahli media dari lingkup dosen Teknik Informatika dan dosen Fakultas Studi Islam. 2) Dokumen, instrumen ini merupakan catatan peristiwa yang sudah berlalu. Seperti data dosen dan mahasiswa, kurikulum, dan data lain yang diperlukan.

Teknik analisis data yang digunakan adalah analisis deskriptif kualitatif dan kuantitatif. Teknik analisis data wawancara melalui 4 tahapan, yaitu pengumpulan data, reduksi data, penyajian data, dan menarik kesimpulan/ verifikasi. Hasil data angket tentang kualitas e-learning dan persepsi dosen dan mahasiswa diolah menggunakan metode statistik deskriptif. Prosedur penelitian dan pengembangan ini adalah analisis kebutuhan calon pengguna dan review hasil riset dan informasi terkait produk yang dikembangkan, penyusunan rencana yang ingin dicapai pada spesifikasi produk yang dikembangkan, mengembangkan bentuk awal program, validasi desain oleh ahli media, revisi desain berdasarkan saran atau masukan ahli media, uji coba terbatas pada beberapa calon pengguna, revisi, uji coba yang kedua melalui penelitian eksperimen, revisi untuk penyempurnaan perangkat yang dikembangkan. Penelitian ini terbatas pada pengembangan saja, yaitu pada tahapan uji coba terbatas. Untuk uji

$10 \quad$ Ibid. coba dan meneliti pengaruhnya pada berbagai variabel lain akan dilakukan pada penelitian selanjutnya.

\section{HASIL PENELITIAN}

\section{Spesifikasi Produk yang dikembangkan}

Situse-Learningyangdikembangkanberada pada subdomain http://fsi.elearninguniska-mab. com dengan menggunakan aplikasi Moodle versi 3.1. Tema yang dipasang pada situs e-learning adalah Campus versi 3.1, dengan halaman unduh: https://moodle.org/plugins/ theme_campus.

Prosedur pendaftaran dan penggunaan situs e-learning bagi mahasiswa adalah sebagai berikut.

1) Mahasiswa mendaftar pada situs e-learning menggunakan metode email-based selfregistered, yaitu mahasiswa menekan tombol login, lalu mengisi formulir pendaftaran, lalu mengaktifkan akunnya melalui email pribadi yang didaftarkan.

2) Pengguna login ke situs $e$-learning. Mahasiswa yang terdaftar sebagai penggguna e-learning akan memiliki peran sebagai authentical user (pengguna terdaftar).

3) Mahasiswa mendaftar pada mata kuliah tersebut dengan menggunakan sandi mata kuliah yang dapat diperoleh dari teacher (dosen pengampu mata kuliah) dan administrator.

4) Mahasiswa mengakses materi kuliah dan mengikuti kegiatan mata kuliah.

Prosedur pendaftaran dan penggunaan situs e-learning bagi dosen adalah sebagai berikut.

1) Dosen mendaftar pada situs e-learning menggunakan metode email-based selfregistered, yaitu dosen menekan tombol 
login, lalu mengisi formulir pendaftaran, lalu mengaktifkan akunnya melalui email pribadi yang didaftarkan.

2) Pengguna login ke situs e-learning. Dosen yang terdaftar sebagai penggguna e-learning akan memiliki peran sebagai authentical user (pengguna terdaftar).

3) Administrator mengubah peran akun dosen menjadi peran teacher sehingga akun dosen yang telah terdaftar memiliki hak akses untuk mengelola mata kuliah secara mandiri, seperti membuat, mendaftar, dan mengelola mata kuliah.

4) Dosen masuk ke situs e-larning, kemudian mendaftar dirinya secara mandiri pada suatu mata kuliah yang diampunya dengan memilih peran teacher.

Halaman mata kuliah disusun dan dikelompokkan berdasarkan nama semester. Seluruh halaman mata kuliah Program Studi PGMI telah tersedia pada situs e-learning dengan menggunakan format topik. Setiap dosen memiliki hak akses penuh pada suatu mata kuliah, seperti membuat mata kuliah, mendaftarkan dirinya atau orang lain pada suatu mata kuliah, mengubah sandi pendaftaran mata kuliah, mengisi konten dan aktivitas pembelajaran pada halaman mata kuliah. Selain halaman mata kuliah, e-learning yang dikembangkan juga memiliki halaman penyimpanan arsip program studi dengan format Folder, halaman forum tanya jawab seputar penggunaan e-learning, dan halaman penilaian kinerja dosen.

Adapun fitur penambahan bahan ajar yang tersedia pada halaman mata kuliah adalah sebagai berikut.
1) Modul Page (Satu Halaman)

Modul Page adalah bahan ajar berupa halaman internet yang dapat digunakan pengajar untuk memasukkan bahan ajar yang bervariasi, seperti teks, gambar, URL, dan video pada sebuah halaman website.

2) Modul Buku

Modul Buku digunakan untuk menampilkan bahan ajar pada beberapa halaman yang berbeda dengan disertai daftar isi yang berfungsi sebagai navigasi pembaca. Materi bahan ajar yang ditampilkan pada modul buku tidak terbatas pada teks saja, tetapi pengajar juga bisa menambahkan foto, video, dan URL situs lain. Perbedaan bahan ajar format buku dengan format page terletak pada jumlah halamannya yang terdiri dari beberapa halaman dan disertai dengan daftar isi.

3) Modul File

Modul file digunakan untuk menambahkan sebuah file bahan ajar pada halaman mata kuliah sehingga file tersebut dapat diunduh dan digunakan peserta didik yang terdaftar pada suatu mata kuliah sebagai sumber belajar mata kuliah. Jenis file yang bisa diunggah ke e-learning cukup beragam, seperti: dokumen teks (.ppt, .pdf, .doc/docx, .txt), audio (.mp3), video (.mp4, .flv, SCORM), animasi (.swf), gambar (.png, .gif, .jpg), folder/zip/rar (.zip, folder), dan lain sebagainya.

4) Modul Label

Modul Label digunakan untuk menuliskan dan menampilkan bahan ajar langsung pada halaman mata kuliah. Tampilannya dapat berupa catatan singkat, gambar, audio, video, dan URL sebuah situs. 
5) Modul URL

Modul "URL" digunakan untuk memasukkan URL (alamat website) pada halaman mata pelajaran agar pelajar dapat terhubung ke sebuah materi perkuliahan di halaman website yang lain. Misalnya ke Wikipedia, Youtube, dan lainnya. File ini juga dapat disisipkan dalam teks editor yang ada. Bahan Ajar format $U R L$.

Adapun fitur aktivitas pembelajaran yang tersedia pada halaman mata kuliah adalah sebagai berikut.

1) Forum

Modul forum digunakan untuk melaksanakan diskusi dua arah antara guru dengan peserta didik atau sesama peserta didik dalam sebuah halaman website. Setiap peserta didik dalam forum tersebut bisa bertanya, membalas pesan, menanggapi, dan menyanggah suatu topik dengan mengetikkannya pada sebuah kolom teks editor.

\section{2) Chating}

Modul Chating digunakan untuk berkirim pesan antara pengajar dengan peserta didik atau antara peserta didik secara realtime (langsung). Modul juga bisa ditambahkan guru pada bagian atas sesi agar peserta didik dapat berkirim pesan atau melakukan tanya jawab dengan guru atau peserta didik lain melalui modul Chatting. Ketersediaan Chat dapat diatur untuk kegiatan sepanjang waktu, atau satu kali saja atau mungkin diulang pada waktu yang sama pada setiap hari atau setiap minggu.

\section{3) Web conference}

Modul web conference digunakan pengajar untuk melaksanakan pembelajaran tatap muka online menggunakan halaman website dan kamera PC/ Laptop. Plugin yang digunakan untuk web conference adalah BigBlueButton. Fitur-fitur plugin ini antara lain berbagi suara, live video, slide powerpoint, polling, ikon emote (termasuk mengangkat tangan), kolom chating (obrolan), dan desktop komputer presenter.

4) Assignment (Penugasan)

Modul assignment digunakan pengajar untuk menugaskan, mengumpulkan tugas dan menilai tugas peserta didik secara online dengan disertai keterangan pengerjaan dan batasan yang jelas. Fitur penyerahan tugas terdiri dari dua bagian, yaitu online submission (pengetikan tugas langsung pada kolom teks) dan file submission (penyerahan file tugas).

5) Kuis

Modul kuis digunakan pengajar untuk membuat kuis dengan berbagai macam bentuk soal, menyimpan soal pada bank soal, menyajikan soal-soal kepada peserta didik dengan petunjuk yang rinci, dan memberi penilaian serta umpan balik kepada peserta didik melalui halaman e-learning. Selain itu, pengajar juga bisa mengamankan kuis dengan sandi, mengatur waktu tersedianya, batas waktu pengerjaan, batas waktu pengulangan dan penyajian soal secara acak atau urut.

6) Survei

Modul survei adalah modul yang berisi instrumen terverifikasi untuk menilai dan merangsang proses pembelajaran online. Pengajar tidak dapat mengubah isi instrumen ini, karena modul survei ini sudah disediakan untuk mengumpulkan informasi dari peserta didik tentang lingkungan belajar online dan perkembangan pola pikir mereka dalam proses pembelajaran online. 
7) Choice

Modul Choice adalah media jejak pendapat dengan satu buah pertanyaan untuk mengumpulkan persepsi dan pendapat peserta didik dengan cepat. Fitur ini juga membolehkan peserta didik untuk mengubah pilihan mereka beberapa kali sebelum tanggal penguncian jawaban tiba. Misalnya, persepsi masyarakat tentang lokasi wisata, dan sebagainya.

8) Feedback dan Questionnaire

Modul Feedback dan Questionnaire digunakan pengajar untuk membuat kuesioner dengan berbagai macam pertanyaan untuk mendapatkan umpan balik. Item instrumen kuesioner terdiri dari beberapa pilihan jenis pertanyaan. Perbedaan fitur kuesioner dengan fitur kuis adalah terletak pada tujuannya, yakni kuis untuk menguji dan menilai para responden, sedangkan kuesioner untuk mengumpulkan data.

Selain fasilitas di atas, setiap pengajar juga dapat menyimpan file pribadinya pada fitur Private files. Fitur ini berfungsi untuk menyimpan dan mengamankan data pribadi pada server, memudahkan pengguna dalam mengaksesnya menggunakan berbagai perangkat elektronik, dan lebih praktis saat membagikannya kepada peserta didik, dan mengurangi pemakaian kertas dan ruang penyimpanan dokumen cetak.

Situs e-learning yang dikembangkan juga telah dapat diakses menggunakan smartphone, yakni dengan menggunakan aplikasi browser dan aplikasi Moodle Mobile yang tersedia pada Google Playstore. Dengan aplikasi ini, pengajar dan peserta didik bisa membaca bahan ajar, mengunduh file materi pelajaran, mengisi polling, mengirim dan memeriksa tugas, melaksanakan ujian online, menulis atau membalas topik di forum dan berkirim pesan menggunakan modul chating dengan cepat dan menggunakan tampilan yang sederhana.

\section{Penilaian Ahli Media}

Ahli media yang dipilih berasal dari dosen Program Studi Teknik Informatika sebagai ahli di bidang aplikasi e-learning dan dosen Program Studi Pendidikan Guru Madrasah Ibtidaiyah sebagai ahli desain dan konten e-learning. Beberapa komentar ahli media yang telah direvisi antara lain adalah:

1) Penerjemahan beberapa istilah asing dalam sistem e-learning

2) Penambahan halaman tutorial pada e-learning

3) Perbaikan sistematika buku panduan

Setelah perbaikan dilakukan, seluruh ahli media menyatakan bahwa e-learning dapat digunakan sebagai media pembelajaran dan telah mencukupi persyaratan sebuah sistem e-learning.

\section{Respon Pengguna}

Respon pengguna terhadap e-learning yang dikembangkan cukup baik, hal tersebut ditunjukkan oleh jawaban pengguna dalam angket yang disebarkan, yaitu: 1) Kebanyakan pengguna $(87,5 \%)$ menyatakan tertarik dalam menggunakan e-learning. 2) Semua pengguna menyatakan dapat menggunakan e-learning dengan mudah, 3) Kebanyakan pengguna menyatakan jarang (95\%) mengalami kesulitan saat mengakses situs e-learning, 4) Modul yang tersedia pada e-learning telah mencukupi kebutuhan pengguna, dan 5) Semua pengguna yakin bahwa e-learning mampu membantu mereka untuk melengkapi proses pembelajaran tatap muka. 
Adapun beberapa temuan peneliti mengenai sikap pengguna dalam menggunakan e-learning adalah sebagai berikut.

1) Kepercayaan diri pengajar dan peserta didik terhadap kemampuannya dalam menggunakan komputer berhubungan erat dengan intensitasnya dalam menggunakan e-learning.

2) Ketersediaan infrastruktur seperti komputer dan jaringan internet yang memadai masih menjadi keluhan utama para pengguna e-learning.

3) Motivasi belajar peserta didik untuk belajar mandiri memiliki hubungan yang erat dengan kualitas dan intensites penggunaan e-learning sebagai media dan sumber belajar mandiri.

4) Penggunaan e-learning memerlukan kerjasama dan komitmen antara pimpinan, para dosen, dan mahasiswa.

5) Kelengkapan dan kualitas konten e-learning juga menjadi faktor yang mempengaruhi motivasi peserta didik dalam memanfaatkan e-learning.

\section{KESIMPULAN}

Hasil penelitian ini telah berhasil mengembangkan sebuah e-learning yang dinilai layak untuk digunakan sebagai media pembelajaran dan penilaian. Hasil penelitian ini perlu dilanjutkan dengan penelitian tentang pengaruh penggunaan e-learning terhadap motivasi, efikasi diri, kualitas pembelajaran, dan prestasi belajar peserta didik.

\section{E. DAFTAR PUSTAKA}

Admin. (2008, 7 31). Moodle, Portal E-Learning. Diambil kembali dari Kompas Tekno: http://tekno.kompas. com/read/2008/07/31/0719116/moodle. portal. e-learning.
Admin. (2017, 23 2). About Moodle. Diambil kembali dari Moodle: https://docs. moodle.org/32/en/About_Moodle.

Agung, D. A. (2012). Penerapan E-Learning dalam Pembelajaran. Seruni Seminar Riset Unggulan Nasional Informatika dan Komputer, 1(1), 45.

Arifin, Zainal, (2012), Penelitian Pendidikan: Metode dan Paradigma Baru, Bandung: PT. Remaja RosdaKarya.

Darmawan, D. (2014), Pengembangan E-Learning: Teori dan Desain, Bandung: PT. Remaja Rosdakarya.

Kristo, F. Y. (2008, 08 21), Apa Kendala E-Learning di Indonesia? Diambil kembali dari Detiknet: http://inet. detik.com/read/2008/08/21/171452/ 992295/398/apa-kendala-e-learning-diindonesia.

Limniou, M. \&. (2010), “Teachers' and students' perspectives on teaching and learning through virtual learning environments." European Journal of Engineering Education, 35(6), 645-653.

Marikar, F. M. (2016), "Effectiveness of MOODLE in Education System in Sri Lankan University". International Journal of Modern Education and Computer Science, 8(2), 54.

Martín-Blas, T. \&.-F. (2009). "The role of new technologies in the learning process: Moodle as a teaching tool in Physics." Computers \& Education, 52(1), 35-44. 
